\title{
PENINGKATAN KETERAMPILAN SUMBER DAYA MANUSIA PMI KOTA TARAKAN MELALUI PELATIHAN BERBASIS TEKNOLOGI INFORMASI
}

\author{
Muhammad Fadlan', Indra Tri Saputra ${ }^{2}$ \\ ${ }^{1,2}$ Program Studi Sistem Informasi \\ STMIK PPKIA Tarakanita Rahmawati \\ Jl. Yos Sudarso No. 8, Tarakan 77111, Kalimantan Utara \\ Email: ${ }^{1}$ fadlan@ppkia.ac.id
}

Received: Mei 2020; Accepted : Juni 2020; Published : Juli 2020

\begin{abstract}
Abstrak
Di era teknologi informasi ini, peningkatan keterampilan sumber daya manusia dalam menggunakan komputer di setiap organisasi harus selalu dilakukan secara berkesinambungan. Palang Merah Indonesia (PMI) Kota Tarakan merupakan salah satu organisasi publik yang bergerak dibidang kemanusiaan. Kondisi yang ada saat ini, Sumber Daya Manusia (SDM) PMI Kota Tarakan masih membutuhkan berbagai keterampilan dalam menggunakan komputer, khususnya terkait dengan aplikasi pengolah kata dan angka yang sederhana, terutama dalam membuat laporan dan berbagai jenis surat. Oleh karena itu, dalam kegiatan pengabdian masyarakat ini diusulkan sebuah program pelatihan komputer untuk meningkatkan keterampilan SDM di PMI Kota Tarakan. Kegiatan dilakukan dengan metode training / pelatihan. Hasilnya, para peserta dapat mengikuti dengan baik setiap materi yang studi kasus yang diberikan. Bahkan, sebagian besar peserta berharap kegiatan serupa dapat dilakukan secara rutin. Ini karena besarnya manfaat yang diterima oleh peserta melalui aktivitas pelatihan tersebut.
\end{abstract}

Kata Kunci: komputer; pelatihan; pengabdian masyarakat; PMI; sumber daya manusia

\section{Abstract}

In this era of information technology, improving human resource skills in using computers in every organization must always be done continuously. PMI Kota Tarakan is one of the public organizations engaged in humanity. In the current conditions, the PMI Kota Tarakan Human Resources (HR) still needs a variety of skills in using computers, especially related to simple word and number processing applications, especially in making reports and various types of letters. Therefore, in this community service activity a computer training program is proposed to improve HR skills at PMI Kota Tarakan. This service activity is carried out by training methods. As a result, the participants were able to properly follow each material that the case study provided. In fact, most participants hoped that similar activities could be carried out routinely. This is because of the large benefits received by participants through the training activities.

Keywords : computer; community service; human resources; PMI; training 


\section{Latar Belakang Masalah}

Seiring dengan perkembangan teknologi informasi, maka sudah sewajarnya setiap organisasi dapat melakukan berbagai kegiatan untuk mengembangkan kemampuan maupun kualitas dari sumber daya manusia (SDM) di organisasi tersebut. Salah satu aspek kemampuan SDM yang harus ditingkatkan adalah kemampuan SDM dibidang teknologi informasi dan komunikasi (TIK). Setiap organisasi setidaknya dituntut untuk mampu menetapkan berbagai strategi khusus dalam meningkatkan kemampuan SDM dibidang TIK tersebut [1], [2], [3]. Salah satu strategi yang dapat dilakukan adalah melalukan pelatihan komputer terhadap setiap SDM yang dimiliki oleh organisasi. Pelatihan seperti ini juga penting untuk mendukung kinerja dari sebuah organisasi [4], [5].

Palang Merah Indonesia (PMI) merupakan sebuah organisasi di Indonesia yang bergerak dibidang kesehatan dan kemanusiaan, serta termasuk salah satu organisasi yang paling dibutuhkan oleh masyarakat [6]. Dalam perkembangannya, PMI sebagai organisasi publik juga membutuhkan teknologi informasi dalam membantu setiap kegiatan didalam organisasi tersebut. Sebagai contoh adalah pemanfaatan sistem informasi dalam melakukan pendataan stok darah yang ada di PMI [7], [6].

Palang Merah Indonesia (PMI) Kota Tarakan merupakan salah satu cabang PMI yang berada di Provinsi Kalimantan Utara [8]. Berdasarkan, kondisi yang ada saat ini, Sumber Daya Manusia (SDM) PMI Kota Tarakan masih memerlukan peningkatan kemampuan dalam menggunakan aplikasi sederhana dalam melakukan pengelolaan kata maupun angka, khususnya dalam membuat laporan maupun berbagai jenis surat yang diperlukan oleh PMI Kota Tarakan. Salah satu cara yang dapat dilakukan untuk mengatasi permasalahan adalah melakukan pelatihan komputer dengan menggunakan aplikasi Microsoft Office Word dan Excel [9], [10].

Berdasarkan hal tersebut, maka pada kegiatan pengabdian ini diusulkan sebuah pelatihan komputer untuk meningkatkan keterampilan SDM di PMI Kota Tarakan. Diharapkan melalui pelatihan ini dapat meningkatkan kemampuan SDM di PMI Kota Tarakan dalam menggunakan komputer untuk memenuhi setiap kebutuhan PMI Kota Tarakan. Adapun manfaat yang diharapkan dapat diambil dari kegiatan ini, antara lain bagi pihak PMI Kota Tarakan, diharapkan melalui kegitan ini meningkatkan keterampilan sumber daya manusia di PMI Kota Tarakan dan dapat meningkatkan reputasi dosen maupun institusi perguruan tinggi di kalangan masyarakat sekitar, karena memiliki peran dalam membantu organisasi publik seperti PMI dalam meningkatkan keterampilan sumber daya manusia di bidang komputer.

Tujuan utama dari kegiatan pelatihan ini adalah untuk meningkatkan keterampilan sumber daya manusia di PMI Kota Tarakan dalam mengoperasikan aplikasi pengolah kata dan angka (Microsoft Office) dengan menggunakan komputer, sehingga mampu memudahkan pihak PMI Kota Tarakan dalam menyelesaikan beberapa proses kerja dengan menggunakan komputer.

\section{Metode}

a. Lokasi Kegiatan

Pelatihan dilaksanakan selama 6 hari dengan durasi selama 90-120 menit per harinya. Kegiatan pengabdian ini dilakukan di Markas Palang Merah Indonesia (PMI) Kota Tarakan, yang terletak di Jl. Pulau Irian No.40, Kp. Satu Skip, Tarakan Tengah, Kota Tarakan, Kalimantan Utara 77122. 


\section{b. Pelaksana dan Peserta}

Pelaksana kegiatan pelatihan ini adalah dosen program studi sistem informasi STMIK PPKIA Tarakanita Rahmawati. STMIK PPKIA Tarakanita Rahmawati merupakan salah satu perguruan tinggi swasta yang berada di provinsi Kalimantan Utara. Sedangkan, peserta dari kegiatan pelatihan ini adalah anggota / staff markas PMI Kota Tarakan.

\section{c. Metode Kegiatan}

Metode yang dilakukan dalam kegiatan ini adalah model training / pelatihan. Dalam pelaksanaannya, setiap harinya tahapan pelatihan ini dibagi kedalam beberapa langkah seperti yang dapat dilihat pada Gambar 1 .
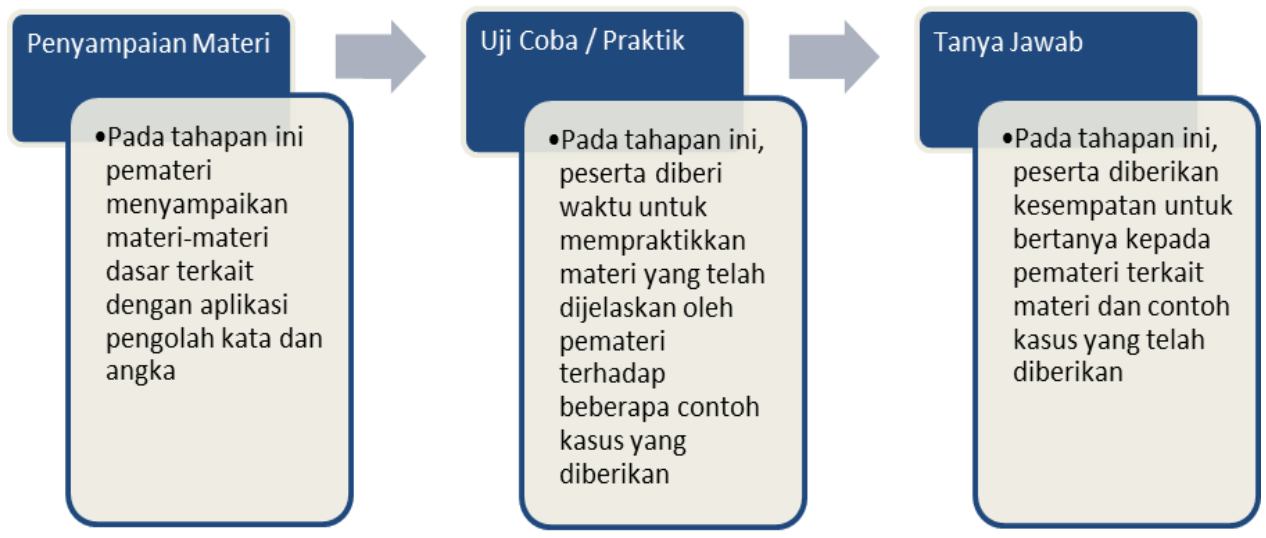

Gambar 1. Tahapan Pelatihan

Adapun materi dalam pelatihan komputer yang dibahas dalam pelatihan ini adalah software Microsoft Office (word dan excel). Microsoft Word merupakan salah satu perangkat lunak yang telah banyak digunakan karena kemudahan dalam pengoperasiannya. Perangkat lunak ini juga mampu memberikan berbagai macam fitur yang dapat digunakan oleh pengguna dalam membantu menyelesaikan berbagai pekerjaan terkait dengan pengolahan kata dengan mudah [9].

Secara keseluruhan rincian materi yang diberikan pada kegiatan ini antara lain :

1. Microsoft Word: Mail Merge

Materi ini terkait dengan pemanfaatan teknik mail merge, khususnya dalam melakukan pengelolaan surat-menyurat di PMI Kota Tarakan. Melalui teknik ini diharapkan dapat mempermudah pihak PMI Kota Tarakan dalam melakukan pengelolaan berbagai jenis surat.

2. Operasi Aritmatika Sederhana

Materi ini terkait dengan penggunaan operasi aritmatika sederhana untuk membuat berbagai macam jenis laporan keuangan yang nantinya dapat diterapkan oleh pihak PMI Kota Tarakan. Operasi aritmatika yang dimaksud antara lain +, -, /, *, sum, average, min, max, hingga count.

\section{d. Evaluasi}

Pada kegiatan ini proses evaluasi dilakukan dengan membagikan kuesioner kepada para peserta terkait dengan proses pelatihan yang telah dilalui. Hasil kuesioner tersebut kemudian di proses untuk mengetahui seperti apa penilaian peserta terhadap pelatihan yang telah diberikan. 


\section{Hasil dan Pembahasan}

Sebelum kegiatan dilaksanakan, terlebih dahulu dilakukan persiapan alat dan bahan pelatihan, menentukan waktu pelaksanaan dan lamanya kegiatan pengabdian bersama dengan tim pelaksana serta menentukan dan mempersiapkan materi yang akan disampaikan dalam kegiatan pengabdian masyarakat. Selama pelatihan, masing-masing peserta memiliki perangkat komputer / laptop sendiri yang telah tersedia di PMI Kota Tarakan, sehingga masing masing peserta dapat mempraktekkan secara langsung apa yang disampaikan tutor. Kondisi awal terkait dengan keterampilan para peserta pelatihan terhadap pemahaman pada materi yang diajarkan adalah hampir sebagian besar peserta masih mengalami kesulitan dalam mengikuti materi yang diajarkan, sehingga pemateri harus menjeleaskan secara rinci setiap materi yang diberikan.

Berdasarkan pada Gambar 1, terdapat 3 tahapan yang dilalui selama proses pelatihan. Tahap pertama adalah tahap penyampaian materi oleh pemateri. Pada tahapan ini, pemateri menyampaikan materi-materi dasar terkait dengan penggunaan perangkat lunak microsoft word. Selain itu, pemateri juga menyampaikan beberapa teknik-teknik penting dalam penggunaan perangkat lunak tersebut. Selanjutnya, pada tahap kedua para peserta diberikan kesempatan untuk melakukan praktik terkait dengan materi yang telah diberikan. Kemudian, tahap terakhir peserta diberikan kesempatan untuk bertanya kepada pemateri. Secara keseluruhan, peserta dapat memahami setiap materi yang diberikan oleh pemateri. Hal ini dapat terlihat dari berbagai studi kasus yang diberikan oleh pemateri yang dapat diselesaikan oleh peserta. Salah satu contoh studi kasus yang diberikan dapat dilihat pada Gambar 2. Sedangkan, salah satu dokumentasi pelatihan dapat dilihat pada Gambar 3.

\begin{tabular}{|c|c|c|c|c|c|c|c|c|}
\hline $\begin{array}{l}2 \\
3\end{array}$ & No & $\begin{array}{c}\text { Tanggal } \\
\text { Transaksi }\end{array}$ & \begin{tabular}{|c|} 
Kode \\
Barang
\end{tabular} & $\begin{array}{l}\text { Nama } \\
\text { Barang }\end{array}$ & Jenis Barang & Harga & Jumlah & Jumlah \\
\hline 4 & 1 & 1-Jul-19 & B-101 & Lan Card & Super LAN 100 Mbps & Rp 200,000 & 10 & Rp $2,000,000$ \\
\hline 5 & 2 & 2-Jul-19 & B-102 & Sound Card & 16 Bit & Rp $\quad 500,000$ & 5 & $\operatorname{Rp} 2,500,000$ \\
\hline 6 & 3 & 3-Jul-19 & B-103 & Main Board & Asus P2BF & Rp $1,125,000$ & 8 & $\operatorname{Rp} 9,000,000$ \\
\hline 7 & 4 & 4-Jul-19 & B-104 & Mouse & Genius PS/2 & 95,000 & 30 & Rp $2,850,000$ \\
\hline 8 & 5 & 5-Jul-19 & B-105 & Keyboard & Genius PS/2 & $\begin{array}{|ll|}\mathrm{Rp} & 175,000 \\
\end{array}$ & 20 & Rp 3,500,000 \\
\hline 9 & 6 & 6-Jul-19 & B-106 & Monitor & GTC Digital & $\operatorname{Rp} 1,125,000$ & 8 & $\operatorname{Rp} 9,000,000$ \\
\hline 10 & 7 & 7-Jul-19 & B-107 & CD-Room & Asus $40 X_{\max }$ & Rp 500,000 & 3 & Rp $1,500,000$ \\
\hline 11 & 8 & 8-Jul-19 & B-108 & VGACard & $16 \mathrm{Mb}$ & Rp 395,000 & 17 & Rp $6,715,000$ \\
\hline 12 & 9 & 9-Jul-19 & B-109 & Active Hub & 3 Com 16 Port & Rp $1,250,000$ & 4 & $\operatorname{Rp} 5,000,000$ \\
\hline 13 & 10 & 10-Jul-19 & B-110 & Disk Drive & Panasonic & Rp 170,000 & 25 & $\operatorname{Rp} 4,250,000$ \\
\hline 14 & \multicolumn{7}{|c|}{ Total pembayaran (pakai SUM) } & Rp 46,315,000 \\
\hline 15 & \multicolumn{7}{|c|}{ Jumlah Minimal pembayaran (pakai MIN) } & Rp $1,500,000$ \\
\hline 16 & \multicolumn{7}{|c|}{ Jumlah Maximal pembayaran (pakai MAX) } & Rp $9,000,000$ \\
\hline 17 & \multicolumn{7}{|c|}{ Rata-rata total pembayaran (pakai AVERAGE) } & $\operatorname{Rp} 4,631,500$ \\
\hline 18 & \multicolumn{7}{|c|}{ Jumlah Data (pakai COUNT) } & 10 \\
\hline 19 & Ket & tentuan Pros & ses & & & & & \\
\hline 20 & \multicolumn{8}{|c|}{ o. Tanggal, Kode Brg, Nama Barang, Jenis Barang, Harga Satuan, Jumlah Beli : Di Inputkan } \\
\hline 21 & \multicolumn{5}{|c|}{ o. Jumlah Bayar : Harga Satuan * Jumlah Beli } & & & \\
\hline
\end{tabular}

Gambar 2. Contoh Studi Kasus Pelatihan 


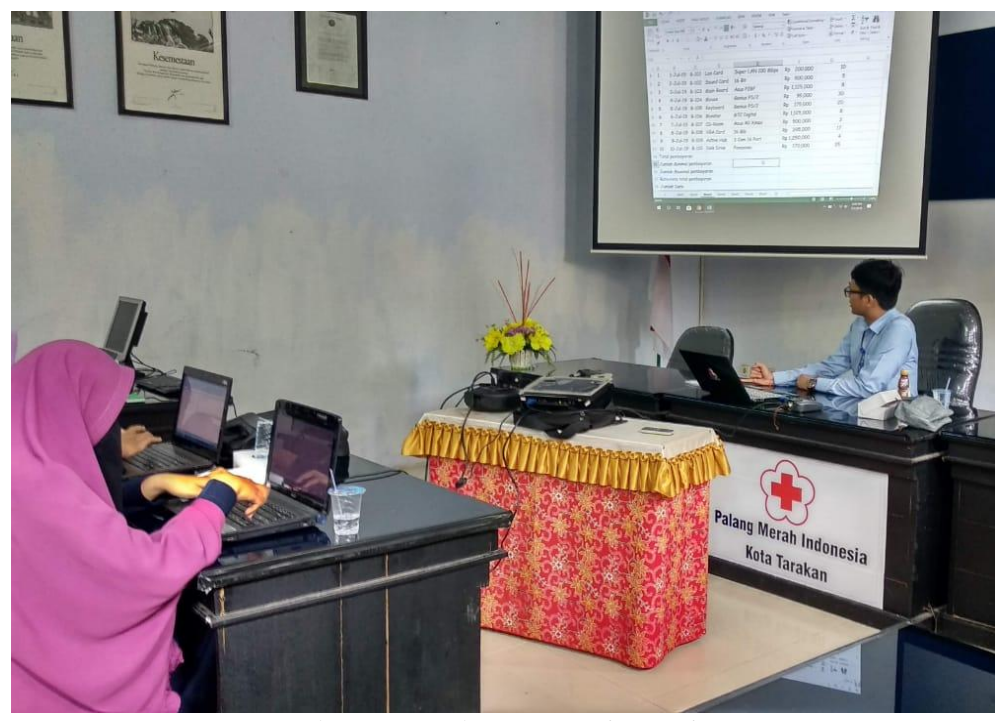

Gambar 3. Dokumentasi Kegiatan

Pada Gambar 3, terlihat pemateri sedang menjelaskan materi terkait dengan pemanfaatan Microsoft Excel dalam membuat laporan keuangan. Terlihat juga salah seorang peserta yang sedang memperhatikan dan mempraktikkan materi yang telah dijelaskan. Selama pelaksanaan kegiatan ini juga ditemukan beberapa kendala. Kendala utama saat pelaksanaan kegiatanbeserta cara penangannannya secara rinci dapat dilihat pada Tabel 1.

Tabel 1. Kendala dan Cara Penanganan

\begin{tabular}{c|l|l}
\hline No & \multicolumn{1}{|c|}{ Kendala } & \multicolumn{1}{c}{ Penanganan } \\
\hline \hline 1 & Trouble pada Perangkat Komputer & $\begin{array}{l}\text { Peserta dipindahkan ke perangkat komputer } \\
\text { lain, agar tetap dapat mengikuti pelatihan }\end{array}$ \\
2 & $\begin{array}{l}\text { Peserta mengalami kesulitan dalam } \\
\text { mempraktikkan kasus yang diberikan }\end{array}$ & $\begin{array}{l}\text { Pemateri memberikan penjelasan secara } \\
\text { langsung dengan mendatangi tempat duduk } \\
\text { peserta yang mengalami kesulitan }\end{array}$ \\
\hline
\end{tabular}

Selanjutnya, untuk mengetahui bagaimana penilaian peserta terhadap pelatihan yang telah diberikan dapat dilihat melalui hasil dari kuesioner yang telah dibagikan. Terdapat beberapa pernyataan yang diajukan pada kuesioner. Daftar pernyataan tersebut mengacu pada ketentuan standar mutu internal perguruan tinggi. Daftar pernyataan dapat dilihat pada Tabel 2.

Tabel 2. Daftar Pernyataan Kuesioner

\begin{tabular}{c|l}
\hline No & \multicolumn{1}{|c}{ Pernyataan } \\
\hline \hline 1 & Kesesuaian materi pelatihan dengan harapan Anda \\
2 & Kemudahan materi pelatihan untuk dipahami \\
3 & Kualitas materi pelatihan \\
4 & Relevansi materi dengan pekerjaan Anda \\
5 & Kemampuan pemateri dalam menyampaikan materi \\
6 & Interaksi pemateri dengan peserta \\
7 & Kebersihan dan kenyamanan ruangan pelatihan \\
8 & Kondisi perangkat pendukung pelatihan \\
\hline
\end{tabular}

Pada Tabel 1, dapat dilihat bahwa terdapat 8 pernyataan yang diajukan dalam kuesioner yang diberikan kepada peserta. Pada kuesioner tersebut, peserta diminta untuk KACANEGARA Jurnal Pengabdian pada Masyarakat 
memilih pilihan jawaban yang tersedia, mulai dari sangat baik (SB) hingga sangat kurang (SK). Secara keseluruhan, dari semua parameter pernyataan yang ada peserta memberikan penilaian "Baik" terhadap pelatihan yang diberikan. Sebagai contoh, hasil penilaian untuk paramater kualitas materi pelatihan dapat dilihat pada Gambar 4.

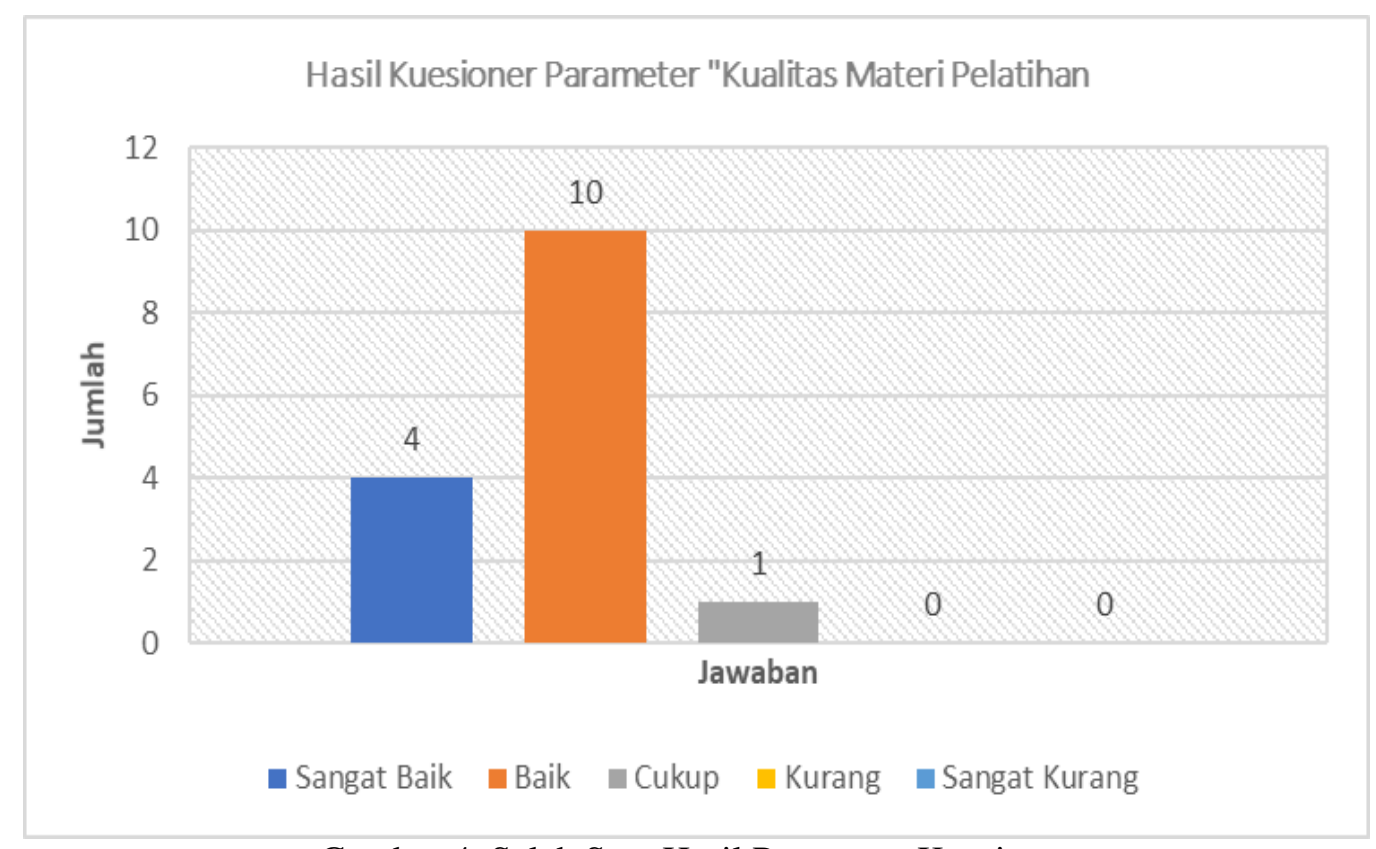

Gambar 4. Salah Satu Hasil Parameter Kuesioner

Berdasarkan Gambar 4, dapat dilihat bahwa dari 15 responden yang memberikan penilaian, terdapat 4 responden memberikan penilaian "sangat baik" terhadap kualitas materi pelatihan, 10 responden memberikan nilai "baik" dan 1 responden memberikan nilai "cukup". Hal ini menunjukkan bahwa materi pelatihan yang diberikan oleh pemateri dianggap baik oleh peserta. Selain menjawab 8 pernyataan yang terdapat dalam kuesioner, peserta juga diminta untuk memberikan tanggapan secara terbuka terhadap pelatihan yang diberikan. Pada tanggapan ini, peserta diminta menuliskan kesan dan pesannya terhadap pelatihan yang telah dilakukan. Hasilnya hampir sebagian besar peserta yang mengisi kuesioner berharap agar kegiatan serupa dapat dilaksanakan secara rutin. Hal ini terjadi karena manfaat yang diterima oleh peserta melalui kegiatan komputer tersebut dirasa sangat besar.

\section{Kesimpulan}

Berdasarkan kegiatan yang telah dilakukan terdapat satu hal penting yang dapat disimpulkan yaitu selama tahapan pelatihan, para peserta dapat mengikuti setiap materi yang diberikan dengan baik. Hal ini terlihat dengan beberapa kasus / pertanyaan yang diberikan oleh pemateri yang dapat diselesaikan oleh peserta pelatihan. Selain itu, melalui pelatihan ini juga mampu meningkatkan kemampuan dasar peserta dalam menggunakan perangkat lunak microsoft office, khususnya dalam membantu menyelesaikan berbagai jenis pekerjaan yang ada. Secara keseluruhan berdasarkan hasil kuesioner, peserta memberikan penilaian bahwa pelatihan ini telah berjalan dengan baik dan sesuai dengan harapan peserta.

Berdasarkan kegiatan pengabdian yang telah dilakukan, maka disarankan kegiatan pelatihan komputer sejenis ataupun yang lainnya dapat terus dijalankan secara rutin. Beberapa materi pelatihan yang dapat dijalankan, antara lain pelatihan jaringan komputer, 
desain grafis, hingga pelatihan dalam pemrograman berbasis website untuk mengembangkan website dari institusi. Hal ini perlu dilakukan untuk meningkatkan keterampilan sumber daya manusia dalam menjalani kehidupan di era teknologi informasi.

\section{Daftar Pustaka}

[1] Yudiastra, P. P., \& Darma, G. S. (2015). Pengaruh Penggunaan Teknologi Informasi, Disiplin Kerja, Insentif, Turnover Terhadap Kinerja Pegawai. Jurnal Manajemen Bisnis, 12(1), 151-176.

[2] Kurnianingsih, I., Rosini, R., \& Ismayati, N. (2017). Upaya Peningkatan Kemampuan Literasi Digital Bagi Tenaga Perpustakaan Sekolah dan Guru di Wilayah Jakarta Pusat Melalui Pelatihan Literasi Informasi. Jurnal Pengabdian Kepada Masyarakat (Indonesian Journal of Community Engagement), 3(1), 61-76. doi:10.22146/jpkm.25370

[3] Mochamad Mas'ud. (2017). Pemanfaatan Teknologi Sistem Informasi untuk Meningkatkan Penjualan Hasil Produk UMKM Logam di Kota Pasuruan. Engagement: Jurnal Pengabdian Kepada Masyarakat, 1(2), 185-197. doi:10.29062/engagement.v1i2.14

[4] Niati, A., Soelistiyono, A., \& Ariefiantoro, T. (2019). Pengembangan Kemampuan Sumber Daya Manusia melalui Pelatihan Komputer Microsoft Office Excel untuk Meningkatkan Kinerja Perangkat Desa Mranggen. E-Dimas: Jurnal Pengabdian Kepada Masyarakat, 10(1), 105. doi:10.26877/e-dimas.v10i1.3557

[5] Nasir, A., \& Oktari, R. (2011). Pengaruh Pemanfaatan Teknologi Informasi dan Pengendalian Intern Terhadap Kinerja Instansi Pemerintah (Studi Pada Satuan Kerja Perangkat Daerah Kabupaten Kampar). Jurnal Ekonomi, 19(02).

[6] Suherman, Y. (2017). SISTEM APLIKASI BANK DARAH PADA PALANG MERAH INDONESIA PAYAKUMBUH. Jurnal Sains Dan Informatika, 3(1), 22. doi:10.22216/jsi.v3i1.2329

[7] Purnama, V. C. (2013). Perancangan Sistem Informasi Inventori Darah Berbasis Web Pada Palang Merah Indonesia Cabang Bantul. Speed-Sentra Penelitian Engineering dan Edukasi, 8(3).

[8] Muhammad, M., Fadlan, M., Hafid, M., \& Fahreza, M. I. (2020). Pengembangan Website Profile PMI Kota Tarakan sebagai Sarana Keterbukaan Informasi Publik. ETHOS (Jurnal Penelitian Dan Pengabdian), 8(1), 5315. doi:10.29313/ethos.v8i1.5315

[9] Ikhwani, Y., Budiman, H., \& Rasyidan, M. (2015). Pelatihan Aplikasi Microsoft Word 2013 Pada SMP HA Johansyah. A Banjarmasin. Jurnal Pengabdian Al-Ikhlas Universitas Islam Kalimantan Muhammad Arsyad Al Banjary, 1(1).

[10] Susilo, J., Pujiatna, T., \& Firmasari, S. (2020). Pembinaan Tata Bahasa dan Bentuk Surat-Menyurat Indonesia Berbasis Microsoft di Desa Mandala, Dukupuntang Kabupaten Cirebon. JPPM (Jurnal Pengabdian Dan Pemberdayaan Masyarakat), 4(1), 173. doi:10.30595/jppm.v0i0.5498 